\title{
Men's use of sexual health services
}

\author{
Steve Pearson, BSc, PhD, Researcher, Centre for Sexual Health Research, University of Southampton, Southampton, UK
}

Correspondence: Dr S Pearson, Centre for Sexual Health Research, Faculty of Social Sciences, University of Southampton, Highfield, Southampton SO17 1BJ, UK. Tel: +44 (0) 2380597770 . Fax: +44 (0) 2380593844.

E-mail: pearson22s@yahoo.co.uk

(Accepted 10 March 2003)

Journal of Family Planning and Reproductive Health Care 2003; 29(4): 190-194

\begin{abstract}
Context and objective. Previous research on users of sexual health services has focused primarily on women. However, a focus on men also is needed to address sexual ill-health. This paper uses various data sources to describe the level of, and trends in, men's use of sexual health services in England.

Data sources. Routine data are presented on clients of family planning clinics (FPCs), Brook Advisory Centres and attendances at genitourinary medicine (GUM) clinics. Cross-sectional surveys used include the National Survey of Sexual Attitudes and Lifestyles, Morbidity Statistics from General Practice and the National Gay Men's Sex Survey.

Results. The number of male clients attending FPCs has increased by $160 \%$ over the 1990s. Most of this increase is due to more men obtaining condoms. The ages of these clients are unknown, but data from Brook Advisory Centres show an increase among younger men. The one service for which male and female use is approximately equal is GUM. Male cases of sexually transmitted infections and other treatments have increased over the 1990s, although not at the same rate as female cases. Use of GUM clinics by homosexually active men is much greater than by all men. Recent data on men's use of general practice for sexual health are lacking.

Discussion and conclusions. While overall service use among men is still at a comparatively low level, it has increased over the 1990s for some services. Further indepth research should question men's wants and demands from sexual health services.
\end{abstract}

\section{Key message points}

- Apart from genitourinary medicine, men are minority users of sexual health services.

- Men's use of sexual health services has substantially increased over the 1990s.

- More men have been attending family planning and young people's sexual health clinics to obtain condoms.

- In-depth research questioning men about their requirements from sexual health services is needed.

\section{Context}

Legislation in the UK regarding the provision of sexual health services stresses that services be available to any adult, regardless of age, gender or marital status. ${ }^{1,2}$ However, in common with other health services, differentials in uptake of sexual health services exist. This paper focuses on one of the most striking differentials in use, namely gender.

Most research on sexual health services provided by family planning clinics (FPCs) and general practice in the UK has focused on female clients. This bias reflects the fact that the majority of these clients are female. From the 1920s onwards, pioneers of family planning stressed the need to improve women's health and free them from the burden of unwanted childbearing. ${ }^{3}$ The high uptake of the pill in the UK in the 1960s transferred much of the responsibility for family planning to the female user.

However, the past two decades have seen increasing interest in the role men play in sexual relationships and contraceptive use. The emergence of HIV in the mid-1980s prompted research into condom use, and hence the role of male homosexual and heterosexual partners. A continuing high rate of teenage pregnancy ${ }^{4}$ and rising rates of sexually transmitted infections (STIs) ${ }^{5}$ in the UK suggest that men need to be targeted to improve both men's and women's sexual health.

\section{Objective}

A key element of the National Strategy on Sexual Health and HIV 6 is the provision of appropriate, accessible sexual health services for those individuals who need them. The strategy also states the need for good practice to be evidence-based. To help achieve this objective, this paper catalogues and describes data sources providing information on male clients of sexual health services in England. Published and unpublished routinely collected data, and cross-sectional survey data, are used to describe the level of, and trends in, men's use of sexual health services. Four main types of sexual health services - FPCs, young people's services, genitourinary medicine (GUM) clinics and general practice - are considered separately.

\section{FPCs}

All National Health Service (NHS) Trusts are required to return data annually on clients using their FPC services through clinic attendance or domiciliary visits. ${ }^{7}$ Two return forms have been used since the 1970s: SBL708/9 and KT31. Data presented here are the number of first contacts, so each client is recorded only once in the year (calendar

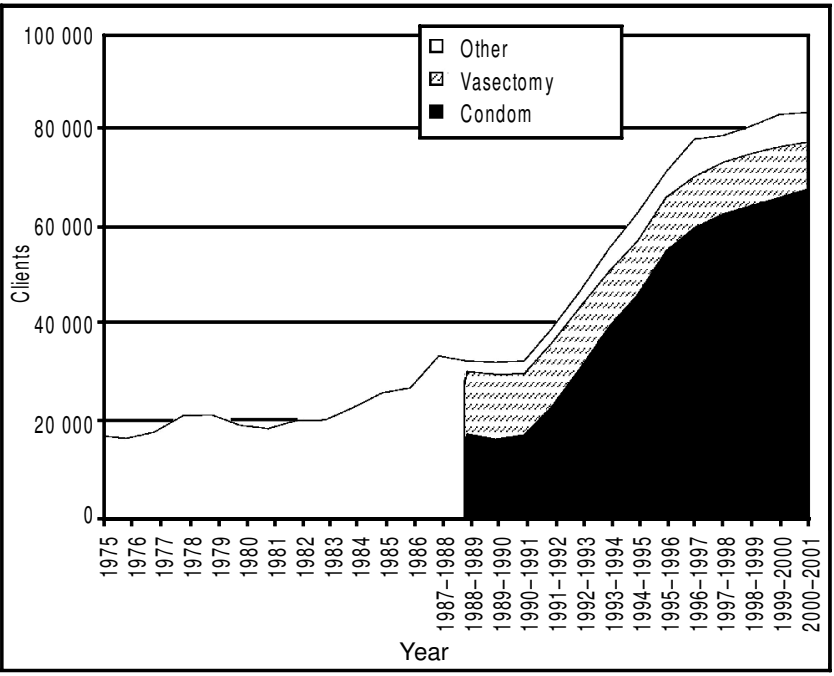

Figure 1 Male family planning clinic clients and reasons for attendance, England 1975 to 2000-2001 
Table 1 Return forms used to collect routine data on family planning clinic clients, England

\begin{tabular}{lll}
\hline & Form SBL708/9 & Form KT31 \\
\hline Coverage & 1975 to 1987-1988 & $1988-1989$ onwards \\
Age of client recorded? & Females: Yes & Females: Yes \\
& Males: Yes & Males: No \\
Reason for attendance recorded? & Females: Yes & Females: Yes \\
& Males: No & Males: Yes \\
Couple attendance & Where a couple are seen together, the first contact is & Where a couple are seen together, only one first contact is \\
& recorded against the sex of the person counselled or the & recorded; where either vasectomy or the male sheath is the \\
& person to whom treatment was mainly given. If a genuine & main method chosen, the first contact is recorded as one \\
& joint consultation occurred, both partners are recorded. & with a man, otherwise as one with a woman. \\
\hline
\end{tabular}

year up to 1986, and financial year from 1987-1988 onwards). Table 1 shows the aggregate information available for clients from the two return forms. Unlike female clients, the age of male clients was collected only up to 1987-1988, and reason for service use collected only from 1988-1989 onwards.

Figure 1 shows the trend in the number of male FPC clients. Men are still in the minority: the 84100 men in 2000-2001 accounted for only $6.6 \%$ of all clients. However, the trend is of increasing male use. Numbers fluctuated from 1975 to 1983 , but steady growth was seen from 1984 to the end of the 1980s. The greatest growth, however, was during the $1990 \mathrm{~s}$, with the number of male clients increasing by $160 \%$ by the end of the decade.

Looking at reasons for FPC use from 1988-1989 onwards, nearly all the growth in male use is accounted for by men obtaining condoms. This group accounted for $81.1 \%$ of male clients in 2000-2001. Over the period 1988-1989 to 2000-2001, the number of men attending for condoms increased by $291.2 \%$, for other reasons $183.4 \%$, whereas vasectomy decreased by $24.5 \%$.

Data on the age of male clients were collected in aggregate form from 1975 to 1987-1988 (L. Lancucki, Department of Health, London, UK, 2001, personal communication). Over this period, the age profile of male clients became younger. The percentage of male clients aged 20-34 years remained constant at around 50\%, while those aged 19 years or under increased from $2.7 \%$ in 1975 to $12.2 \%$ in 1986 .

Service use varies by NHS region. In 2000-2001, London accounted for $24.9 \%$ of female clients, but only $12.6 \%$ of male clients. Conversely, Trent, North West and West Midlands regions show greater relative success in attracting male clients. The individual provider with the greatest success in attracting male clients is Tower Hamlets Healthcare, with $31.1 \%$ of its 3480 clients being male.

\section{Young people's services}

During the 1990s, more sexual health services were targeted towards young people. Two surveys in 1996 identified around 80 sexual health services in England providing services aimed at young people.$^{8,9}$ Many of these services receive funds from the NHS and will therefore submit client data on the KT31 FPC return form. However, published aggregate data are not presented by individual service, and so the level of male attendance at all young people's services is unknown.

A search by the author of the 560 documents collected in a survey of young people's sexual health services 8 produced 34 data values on the sex of clients attending certain young people's services between 1986 and 1996-1997. The incompleteness of these data and the shortage of data on the same service over time hinder the identification of a trend. However, wide variation between services was apparent, with young men accounting for between $1 \%$ and $46 \%$ of clients.
Brook Advisory Centres are a network of centres in the UK offering young people contraceptive and counselling services. Brook collates and publishes client data annually using the KT31 return form, ${ }^{10}$ and also records the age of male clients. Brook has long recognised the importance of encouraging young men to use their services. ${ }^{11}$ Figure 2 shows the number and sex of first contact clients at Brook Advisory Centres between 1986 and 2000-2001. During this period, Brook increased their number of branches operating in the UK from seven to 18. Over the 1990s the percentage of male clients increased steadily, accounting for $11.2 \%$ of the 102000 clients seen in 2000-2001. The age profile of male clients has also been getting narrower and younger. In 1988-1989, 40.2\% of male clients were aged 19 years or under, as compared with $75.3 \%$ in 2000-2001.

\section{Couple attendance}

The discussion so far has been in terms of individual clients; however, some clients attend services as a couple. Table 1 shows how the two FPC return forms record this event. The current KT31 form instructs services to record only the couple member to whom the main method of contraception chosen is prescribed. The man will be recorded as the client only when vasectomy or the male condom is chosen.

Does couple attendance affect the accuracy of estimates of male family planning service use? Routinely collected data do not show how many clients use a service as part of a couple. However, using other data on contraceptive method use, it is possible to speculate whether routine data underestimate or overestimate the level of male service use.

The General Household Survey, an annual questionnaire-based survey of around 9000 households, is a good source for estimating patterns of contraceptive method use in Britain. Data from the 1998 survey show that of women aged 16-29 years currently using contraception,

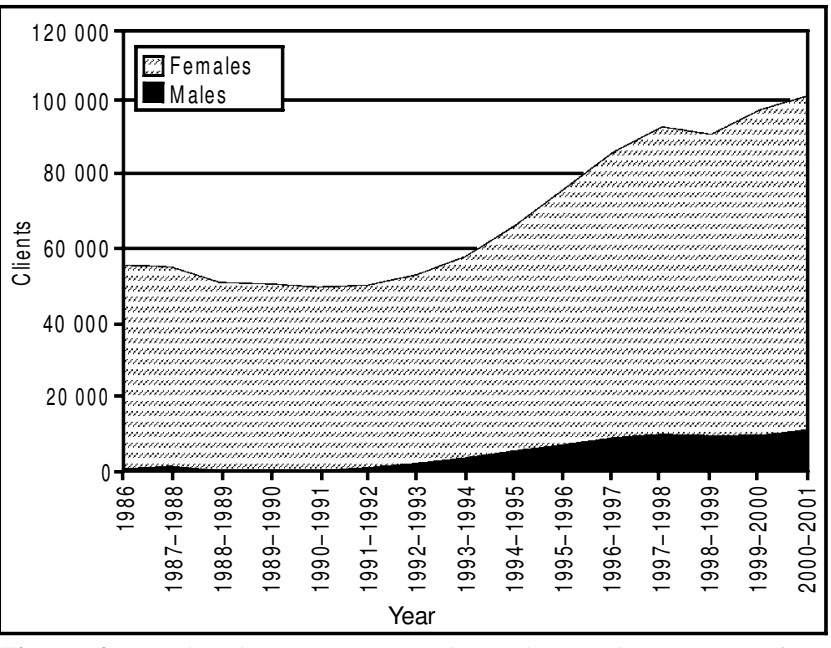

Figure 2 Brook Advisory Centres clients by gender, UK, 1986 to 2000-2001 
Table 2 Young men's reasons for attendance at a Brighton sexual health service, 1992-1993

\begin{tabular}{lc}
\hline Reason & $\%$ \\
\hline Attended with a partner and accompanied her for consultation & 18 \\
Attended with a partner but did not accompany her for consultation & 55 \\
Attended on his own and received consultation himself & 13 \\
Attended for condom supplies only with no consultation & 14 \\
Base (100\%) & 77 \\
\hline
\end{tabular}

twice as many were using a female-prescribed method compared to a male-prescribed method. ${ }^{12}$ Hypothetically, therefore, the female member of a heterosexual couple is around twice as likely as the male member to be solely recorded as the client for couples in this age group who use a family planning service together. Above age 30 years, the ratio of female-prescribed:male-prescribed methods is more even, and therefore this potential bias is removed.

Interesting information on this issue is provided by a sexual health service in Brighton that recorded all attendances of young men over an 8-month period in 1992-1993, categorised in Table $2 .{ }^{13}$ Note that $73 \%$ of the men attended as part of a couple. However, $55 \%$ were not involved in the consultation, merely accompanying their partner to the service venue. Whether these men actually used the service is debatable, but the behaviour may imply the decision to use the service was made jointly by the couple.

\section{GUM clinics}

GUM clinics in England offer advice, counselling, testing and treatment of STIs and, increasingly, general sexual health services including the provision of contraception. ${ }^{14}$ The Public Health Laboratory Service (PHLS) collects routine data on the number of cases seen at GUM clinics in England on the quarterly KC60 return form. ${ }^{5}$ Unlike the KT31 form for family planning services, individuals may be recorded more than once if they repeat attendance during the year. Aggregate data are available on episodes of STIs requiring treatment ('diagnoses'), and other sexual health services provided ('workloads'). The sex of the client is recorded for all cases, the age group for selected conditions, and male sexual orientation for selected conditions.

Figure 3 shows the number of diagnoses and workloads at GUM clinics in England from 1971 to 1999.5 As compared with other sexual health services, the number of male cases is 1971 to $1999^{5}$ (and P. Deeks, PHLS, London, UK, 2001, personal communication). As compared with other sexual health services, the number of male cases is much higher, and the ratio of male:female cases is currently

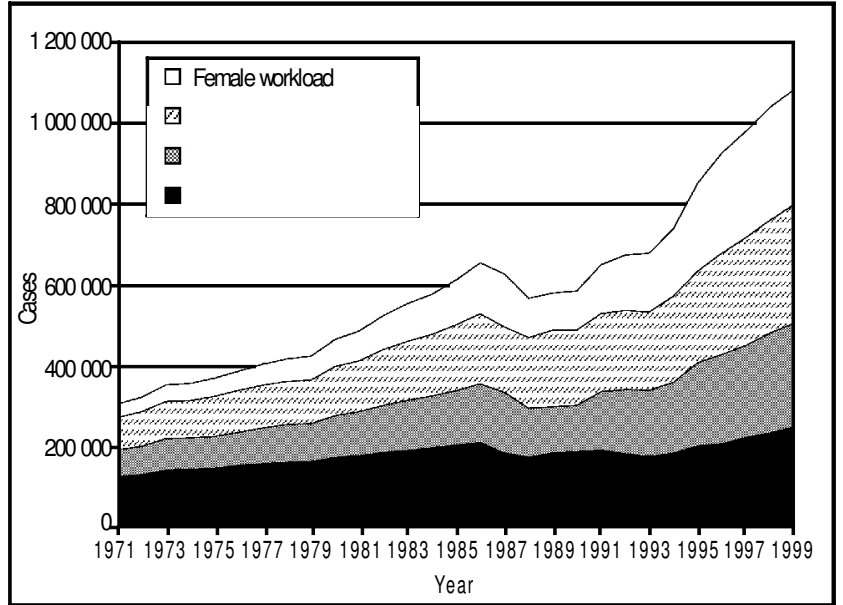

Figure 3 Genitourinary medicine clinic cases by gender, England, 1971-1999
Table 3 Men's sexually transmitted diseases clinic attendance by age group, National Survey of Sexual Attitudes and Lifestyles 1990-1991 a

\begin{tabular}{lllllll}
\hline \multicolumn{7}{c}{ Age group (years) } \\
\cline { 2 - 7 } & $16-19$ & $20-29$ & $30-39$ & $40-49$ & $50-59$ & All \\
\hline Last year & 1.8 & 1.7 & 0.6 & 0.6 & 0.2 & 0.9 \\
Last 5 years & 2.5 & 6.4 & 3.3 & 2.3 & 0.5 & 3.5 \\
Ever & 2.5 & 8.3 & 12.3 & 9.1 & 3.9 & 8.4 \\
Base (100\%) & 571 & 2173 & 1922 & 1775 & 1197 & 7638 \\
\hline
\end{tabular}

aThe figures given in the first three rows of the table are percentage values.

approximately equal. In $1971,62.6 \%$ of cases were male, but this had declined to $46.4 \%$ by 1999 . The number of male cases has been rising over the 1990s, but at a lower rate than female cases.

Of the 498400 male cases in $1999,48.9 \%$ were diagnoses of STIs. The remaining 'workload' cases were episodes of STIs not requiring treatment (20.4\%), HIV antibody counselling with or without testing $(17.4 \%)$ and other reasons $(13.3 \%)$. Only $0.4 \%$ of male cases were for family planning, as compared with $5.3 \%$ of female cases.

The age pattern of all male users is unknown from routine data. An alternative source of data is the National Survey of Sexual Attitudes and Lifestyles (NATSAL). ${ }^{15}$ This cross-sectional survey, first conducted in 1990-1991, collected data using interviewer-completed questionnaires and self-completion booklets from a sample of around 20000 people aged 16-59 years. Responses from men to the question 'Have you ever attended a sexually transmitted disease (STD) clinic or special (VD) clinic?' are shown in Table 3, categorised by age. A total of $8.4 \%$ of the male respondents reported having ever attended a clinic, and $0.9 \%$ reported attendance within the last year. Recent attendance is more likely to be reported by younger respondents. Multivariate analysis of these data by other authors suggests clinic attendance by a man is most associated with number of heterosexual partners and male sex partnerships being reported. ${ }^{16}$

This latter finding is supported by data from the 1999 National Gay Men's Sex Survey. ${ }^{17}$ A short, self-completion questionnaire was distributed at community pride events, and a post-back questionnaire leaflet distributed to HIV health promotion agencies working with homosexually active men. Responses from men to the question 'When was the last time you went to a sexual health clinic?' are shown in Table 4, categorised by age (F. Hickson, University of Portsmouth, Sigma Research, 2001, personal communication). A total of $65.8 \%$ of the sample report having ever attended a clinic, with $24.0 \%$ attending in the last year. Comparative percentages from the NATSAL data shown in Table 3 are $8.4 \%$ of men having ever attended a clinic, and $0.9 \%$ attending in the last year. Even allowing for the different designs of the two surveys, the difference in the level of service use between homosexually active men and all men is striking.

Table 4 Men's sexual health clinic attendance by age group, 1999 National Gay Men's Sex Survey a

\begin{tabular}{lllllll}
\hline \multicolumn{7}{c}{ Age group (years) } \\
\cline { 2 - 7 } & Under 20 & $20-29$ & $30-39$ & $40-49$ & Above 50 & All \\
\hline Last month & 15.4 & 12.9 & 14.5 & 12.6 & 10.7 & 13.5 \\
Last year & 19.9 & 25.3 & 24.7 & 23.1 & 18.8 & 24.0 \\
Ever & 42.3 & 60.5 & 70.6 & 73.3 & 66.8 & 65.8 \\
Base (100\%) & 442 & 2939 & 3255 & 1346 & 570 & 8552 \\
\hline
\end{tabular}

aThe figures given in the first three rows of the table are percentage values. 
Table 5 Male patients consulting general practice for contraceptive management by age group, Morbidity Statistics from General Practice 1990-1991

\begin{tabular}{lllll}
\hline & \multicolumn{4}{l}{ Age group (years) } \\
\cline { 2 - 6 } & $15-24$ & $25-44$ & $45-64$ & All \\
\hline V25 Contraceptive management & 0.06 & 0.56 & 0.07 & 0.30 \\
V25.0 General counselling and advice & 0.03 & 0.44 & 0.05 & 0.23 \\
V25.2 Sterilisation & $-\mathrm{b}$ & 0.12 & $-\mathrm{b}$ & 0.06 \\
Base (100\%) & 32512 & 72122 & 50013 & 154647 \\
\hline
\end{tabular}

aThe figures given in the first three rows of the table are percentage values. bFewer than 10 cases.

\section{General practice}

Most general practitioners (GPs) offer sexual health services to male and female clients. Under the Prescription Cost Analysis system, national data are available regularly for prescriptions and clients in respect of whom a fee is payable to the GP for providing contraceptive services, for example, oral contraceptive prescriptions or intrauterine device insertion. ${ }^{18}$ However, these services are only prescribed to female clients. The one contraceptive method men would be most likely to obtain, the male condom, is unavailable on prescription.

In 1992, the NHS Executive published guidance for regional health authorities on providing family planning services. ${ }^{19}$ One recommendation was that health purchasers allocate HIV ring-fenced money for condom provision through general practice. Because of these guidelines and aims of meeting The Health of the Nation sexual health targets, some health authorities introduced condom provision schemes in general practice. Locations of schemes included Sheffield, Derbyshire, North Yorkshire, Southampton, ${ }^{20}$ Camden and Islington, ${ }^{21}$ Oxfordshire, ${ }^{22}$ Waltham Forest, ${ }^{23}$ and Eastbourne. ${ }^{24}$ For schemes that have published data, the percentage of clients who are male has been low. For example, $13 \%$ of 269 clients in the Oxfordshire scheme were male, as were $17 \%$ of 73 clients who completed a questionnaire in an evaluation of the Southampton scheme.

Lacking regular attendance data, the decennial Morbidity Statistics from General Practice Study (MSGP) provides a snapshot of reasons why the British population attends general practice. The most recent study in 1991-1992 25 recruited general practices whose patient lists provided a sample of around $1 \%$ of the British population. Over 12 months, all face-to-face patient contacts with a practice were recorded, and reasons for attendance coded according to the International Classification of Diseases, Revision 9 (ICD-9). Dividing the number of contacts by the denominator of patientyears at risk gives an estimate of the proportion of the population consulting during the year. Table 5 presents percentages of men consulting for ICD-9 code V25 'Contraceptive management', which includes counselling, advice and prescription of contraception. These data were only available in aggregate form for broad age groups.

In 1991-1992, an estimated $0.30 \%$ of British men aged 15-64 years consulted general practice for contraceptive management. Although not presented in Table 5, this compares with $14.07 \%$ of women aged 15-64 years. Male consultation is most likely at ages 25-44 years $(0.56 \%)$. The two, four-digit ICD-9 codes that account for the majority of consultations are general contraceptive counselling and advice (V25.0) and sterilisation (V25.2).

\section{Discussion and conclusions}

Various data sources have been used to piece together a picture of men's use of sexual health services. While some useful information is available, this review has been hampered by deficiencies in the routine data collected. No data collection system can address all its user's needs, and the need to collect large volumes of data regularly limits the amount of detail available. However, lack of basic demographic information such as the ages of all male clients of FPCs and GUM clinics prevents the calculation of age-specific rates of service use. Thus, which age groups are more likely to use a service is unknown. Also lacking are reliable estimates of characteristics of male sexual health service users in terms of marital status, socioeconomic status, ethnicity and contraceptive use. A forthcoming paper using data from the Omnibus Survey (S. Pearson and P. Clarke, unpublished data) will address some of these points.

Different patterns and trends are evident for the different sexual health services reviewed. For FPCs and young people's sexual health clinics, male clients are still a minority. However, the 1990s have seen an impressive increase in the number of male clients. Most of this increase is due to men obtaining condoms. Although their ages are unknown, the increase in male clients at Brook Advisory Centres suggests younger men account for part of this increase. Improved service provision for young people and safer sex health promotion encouraging the use of condoms probably help to explain this increase. Because of the way in which couples attending an FPC (or Brook Advisory Centre) are recorded in routine data collection, it is likely that the level of young men's service use is being underestimated. However, lacking data on how many clients attend a service as a couple, the extent of this underestimation is unknown.

The one sexual health service for which male and female use is approximately equal is GUM. These clinics have experienced increasing attendance over the 1990s, and there is evidence they are now having difficulties coping with demand. ${ }^{26}$ This growth not only reflects increased episodes of STIs, but also other reasons including HIV counselling and testing. Results from the second NATSAL conducted in 2000 will provide insight on what types of men are accounting for this increased service use.

Little information is available on men's use of general practice for sexual health. Data from the 1991-1992 MSGP Study suggest how few men use this service. Approximately, for every 50 women aged 15-64 years who attended general practice for contraceptive management, only one man did so. Although data from the General Practice Research Database could provide further useful information on this topic, a fifth MSGP Study in 2001-2002 did not occur. Although the availability of condoms through general practice has improved, the service is fragmentary across health authorities. Until condoms become equitably available throughout primary care, this situation is unlikely to change.

Apart from GUM services, men's overall low use of sexual health services needs explaining. Are men uninterested in using the available services, or are the services inappropriate for their needs? Both explanations are likely to be important, but further research is needed before service uptake increases. For example, case studies of health providers relatively successful and unsuccessful in attracting male clients would suggest characteristics of services popular with men. Lessons can also be learnt from the impressive level of GUM clinic attendance by homosexually active men. However, evidence on good practice must be accompanied by in-depth research questioning men about their wants and demands from sexual health services. 
Acknowledgements

The author wishes to thank Roger Ingham (University of Southampton), Brook Advisory Centres, Pauline Deeks (Public Health Laboratory Service), Alan Hervé (Office for National Statistics), Ford Hickson (Sigma Research) and Lesz Lancucki (Department of Health) for their great help in providing data and answering queries.

Statements on funding and competing interests

Funding. None identified.

Competing interests. None identified.

References

1 Royal Commission on Venereal Disease. Final report of the commissioners (1st edn). London: Her Majesty's Stationery Office, 1916.

National Health Service Act 1977, c.49.

3 International Planned Parenthood Federation. Male involvement in family planning: report of an IPPF staff consultation. London: IPPF, 1984.

4 Office for National Statistics. Annual update: births in 2000 and conceptions in 1999, England and Wales. Popul Trends 2001; 106: 69-72.

5 PHLS, DHSS\&PC and Scottish ISD(D)5 Collaborative Group. Trends in sexually transmitted infections, 1990-1999. London: Public Health Laboratory Service, 2000.

6 Department of Health. Better prevention. Better services. Better sexual health. The National Strategy for Sexual Health and HIV. London: Department of Health, 2001.

7 Department of Health. NHS contraceptive services, England: 2000-01. Bulletin 2001/27. London: Department of Health Statistics Division 2B, 2001

8 Peckham S, Ingham R, Diamond, I. Teenage pregnancy: prevention and programmes. Southampton: University of Southampton, Institute for Health Policy Studies and Centre for Sexual Health Research, 1996.

9 Aggleton P, Chalmers H, Daniel S, et al. Promoting young people's sexual health. A compendium of family planning service provision for young people. London: Health Education Authority, 1996.

10 Brook Advisory Centres. Brook Advisory Centres Annual Report. London: Brook Advisory Centres, annual publication.

11 Frater A. Young men at Brook Advisory Centres. London: Family
Planning Association, 1985

12 Office for National Statistics. Living in Britain. Results from the 1998 General Household Survey. London: The Stationery Office, 1999

13 South Downs Health NHS Trust. Annual Report on Young People's Clinics. Brighton: Morley Street Health Centre, 1993.

14 Walsh J. Family planning provision in genitourinary medicine clinics: a quiet revolution. Br J Fam Plann 1996; 22: 27-30.

15 Wellings K, Field J, Johnson AM, et al. Sexual behaviour in Britain: the National Survey of Sexual Attitudes and Lifestyles. London: Penguin Books Ltd, 1994.

16 Johnson AM, Wadsworth J, Wellings K, et al. Who goes to sexually transmitted disease clinics? Results from a national population survey. Genitourin Med 1996; 72: 197-202.

17 Weatherburn P, Stephens M, Reid D, et al. Vital statistics. Findings from the National Gay Men's Sex Survey, 1999. Portsmouth: University of Portsmouth, Sigma Research, 2000.

18 Department of Health. Prescription cost analysis: England 1998. London: Department of Health, 1999.

19 National Health Service Executive. Guidelines for reviewing family planning services: guidance for regions. London: NHSME, 1992.

20 All cited in Burton RA. Patients' evaluation of a GP condom scheme. $\mathrm{MSc}(\mathrm{Ed})$ thesis, Faculty of Educational Studies, University of Southampton, Southampton, 1996.

21 Parham A, Turner B, Yarwood J. A survey of condom distribution throughout general practice in Camden and Islington. Health Educ J 1995; 54: 143-149.

22 Pengilley L, Kay R. Condom use and distribution from general practice - a study from Oxfordshire. Br J Fam Plann 1995; 20 $108-111$.

23 Davidson N, Lloyd T. Working with heterosexual men on sexual health. Men's Sexual Health Project March 1993 Audit. London: Health Education Authority, 1994.

24 Jones M. Audit of condom issuing in Eastbourne sexual health clinic. Br J Fam Plann 1999; 25: 110-111.

25 Office of Population Censuses and Surveys. Morbidity Statistics from General Practice. Fourth National Study 1991-1992. MB5: 3. London: HMSO, 1995.

26 Djuretic T, Catchpole M, Bingham JS, et al. Genitourinary medicine services in the United Kingdom are failing to meet current demand Int J STD AIDS 2001; 12: 571-572.

\title{
Promoting sexual health services to young men: findings from focus group discussions
}

\author{
Steve Pearson, BSc, PhD, Researcher, Centre for Sexual Health Research, University of Southampton, Southampton, UK
}

Correspondence: Dr S Pearson, Centre for Sexual Health Research, Faculty of Social Sciences, University of Southampton, Highfield, Southampton SO17 1BJ, UK. Tel: +44 (0) 2380597770 . Fax: +44 (0) 2380593844.

E-mail: pearson22s@yahoo.co.uk

(Accepted 10 March 2003)

Journal of Family Planning and Reproductive Health Care 2003; 29(4): 194-198

\begin{abstract}
Context. Recently, increasing interest has been shown in men's reproductive health, sexual behaviour and use of contraception. As the majority of sexual health service clients are female, however, little research has been done on the characteristics and needs of male clients.

Objective. Using data from focus group discussions, this paper considers whether young men need sexual health services, whether current services are appropriate and accessible, and what promotion strategies might increase service uptake.

Design. Nine focus group discussions with 75 men aged 13-21 years at different locations in England.

Results. Young men's decision-making around sexual health may involve seeking advice from a close friend, but is less likely in some male social groups. Use of services by young men is most likely to obtain free condoms, or to remedy a crisis situation. While a young man is becoming familiar with obtaining condoms from a service, the need for a quick, straightforward service seems important. The stereotypical view within the groups was that sexual health
\end{abstract}

services are women-oriented. However, suggestions are given to make services more youth-and male-friendly. Promotion should aim to increase awareness and advance a positive image of a sexual health service.

Discussion and conclusions. Effective promotion campaigns (designed with the input of local young men), combined with appropriate and accessible services, should help to increase service use among young men.

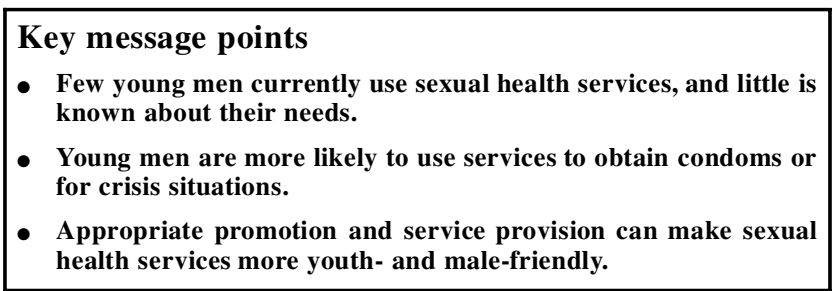

\section{Context}

The past two decades have seen increasing interest in the role men play in sexual relationships, use of contraception, and as clients of sexual health services. The emergence of 